\title{
Continuous subcutaneous infusion for pain control in dying patients: experiences from a tertiary palliative care center
}

\author{
Per Fürst ${ }^{1,2^{*}}$, Staffan Lundström ${ }^{1,2}$, Pål Klepstad ${ }^{3,4,5}$ and Peter Strang ${ }^{1,2}$
}

\begin{abstract}
Background: Continuous subcutaneous infusion (CSCI) via ambulatory infusion pump (AIP) is a valuable method of pain control in palliative care. When using CSCl, low-dose methadone as add-on to other opioids might be an option in complex pain situations. This study aimed to investigate the effects, and adverse effects, of CSCl for pain control in dying patients, with particular interest in methadone use.

Methods: This was an observational cohort study. Imminently dying patients with pain, admitted to specialized palliative inpatient wards and introduced on CSCl, were monitored daily by staff for symptoms (Integrated Palliative Care Outcome Scale - IPOS), sedation (Richmond Agitation and Sedation Scale - RASS), performance status (Eastern Cooperative Oncology Group - ECOG) and delirium (Confusion Assessment Method - CAM).

Results: Ninety-three patients with a median survival of 4 days were included. Of the 47 patients who survived $\geq 3$ days, the proportion of patients with severe/overwhelming pain decreased from 45 to 19\% $(p<0.001)$ after starting $\mathrm{CSCl}$, with only a moderate increase in morphine equivalent daily dose of opioids (MEDD). Alertness was marginally decreased (1 point on the 10-point RASS scale, $p=0.001$ ), whereas performance status and prevalence of delirium, regardless of age, remained unchanged.

Both patients with methadone as add-on (MET, $n=13$ ) and patients with only other opioids (NMET, $n=34$ ), improved in pain control ( $p<0.05$ and 0.001 , respectively), despite that MET patients had higher pain scores at baseline $(p<0.05)$ and were on a higher MEDD $(240 \mathrm{mg}$ vs.133 mg). No serious adverse effects demanding treatment stop were reported.
\end{abstract}

Conclusions: CSCI via AIP is an effective way to reduce pain in dying patients without increased adverse effects. Add-on methadone may be beneficial in patients with severe complex pain.

Keywords: Cancer, Methadone, Opioids, Pain, Subcutaneous, Infusion

\footnotetext{
* Correspondence: per.furst@ki.se

${ }^{1}$ Department of Oncology Pathology, Karolinska Institutet, Stockholm,

Sweden

${ }^{2}$ Palliative Medicine, Stockholms Sjukhem Foundation, Stockholm, Sweden

Full list of author information is available at the end of the article
}

C C The Author(s). 2020 Open Access This article is licensed under a Creative Commons Attribution 4.0 International License, which permits use, sharing, adaptation, distribution and reproduction in any medium or format, as long as you give appropriate credit to the original author(s) and the source, provide a link to the Creative Commons licence, and indicate if changes were made. The images or other third party material in this article are included in the article's Creative Commons licence, unless indicated otherwise in a credit line to the material. If material is not included in the article's Creative Commons licence and your intended use is not permitted by statutory regulation or exceeds the permitted use, you will need to obtain permission directly from the copyright holder. To view a copy of this licence, visit http://creativecommons.org/licenses/by/4.0/ The Creative Commons Public Domain Dedication waiver (http://creativecommons.org/publicdomain/zero/1.0/) applies to the data made available in this article, unless otherwise stated in a credit line to the data. 


\section{Background}

Pain is a common clinical problem in palliative care [1]. Eighty percent of patients with advanced cancer and $67 \%$ of patients with cardiovascular disease or chronic obstructive pulmonary disease will experience moderate to severe pain at the end of their lives [2]. A better understanding of pain mechanisms has improved pain therapy in recent years [3]. Especially, cancer patients in palliative care are adequately treated with low or moderate doses of opioids and only about $10 \%$ need daily morphine doses over $600 \mathrm{mg}$ [4]. However, with progressive deterioration at the end of life, continuous subcutaneous infusions (CSCI) become increasingly important to continue pain control in the dying [5]. The use of an ambulatory infusion pump (AIP), a small, portable pump that delivers medication via a thin subcutaneous catheter, has several advantages for pain control: It ensures a steady infusion of drugs, with reliable absorption if inserted in unaffected tissue, and allows combinations of drugs to be administered parenterally in a manner that is more convenient than repeated and painful injections. Thus, there is no need for an intravenous access $[6,7]$. However, despite encouraging data in palliative care in earlier phases, there is a lack of prospective studies on the use of CSCI in the imminently dying.

Low-dose add-on peroral methadone in combination with other opioids for pain is proposed to be a useful alternative to methadone therapy for better pain control at the end of life [8-12]. The addition of methadone is reported to improve pain relief in complex pain situations but, so far, only peroral or intermittent parenteral administration of low-dose add-on methadone has been studied, routes that are often not feasible in the imminently dying patient [13-15]. Alternative routes of methadone administration are therefore needed and there is a need for further exploration of the effects, and possible adverse effects, of CSCI in this patient group $[13,14]$.

Whereas patient-reported outcomes are encouraged, this is not possible in imminently dying patients, as the majority of them are not able to complete a questionnaire for obvious reasons, such as, terminal delirium, extreme tiredness or lowered level of consciousness. For this reason, very few studies on symptoms and symptom control have been performed in the very last days of life, a period which is important both for the patient and for their families. A way to overcome this problem is to use validated instruments allowing proxy measures, e.g. assessments made by staff.

The primary aim of the study was to report the effects on pain intensity and occurrence of adverse effects, e.g. sedation, confusion, and respiratory depression, when prescribing an AIP for CSCI in imminently dying patients. A secondary aim was to specifically study the effects of the addition of low-dose methadone to a CSCI comprising another opioid in this patient group.

\section{Methods}

The methods and results sections are reported, when applicable, based on the Strengthening the Reporting of Observational Studies in Epidemiology (STROBE) criteria [16].

\section{Study design}

At the specialized palliative care in-patient unit at Stockholm Sjukhem Foundation, we conducted an observational cohort study in patients who were prescribed CSCI via AIP for symptom management during the last days of life. Patients were included from February 1, 2019 to January 22, 2020 and followed up daily, with the last follow-up on January 28, 2020.

\section{Population}

All Swedish-speaking patients over the age of 18 years who were neither sedated nor unconscious and who, during daytime $(7 \mathrm{am}-8 \mathrm{pm})$ as part of their regular care, were prescribed a CSCI of drugs were asked to participate in the study. Inclusions were not possible during other hours due to limited available resources for performing the inclusion procedure.

\section{Definition of total cohort and main study group}

The total cohort consisted of all patients that were included. The main study group consisted of those patients from the main study group, who had pain at inclusion and who survived for three days or more.

\section{Variables}

For every patient, baseline data on age, sex, indication for CSCI, prevalence, intensity and type of pain were registered. Daily registrations covered the previous $24 \mathrm{~h}$ and included medications, site of SC infusion, skin irritation around the SC needle, and other symptoms including patient anxiety, alertness, performance status and occurrence of confusion.

\section{Data sources and rating scales}

As the patients were in an acute dying phase with rapid deterioration from day to day, the study applied exclusively instruments allowing proxy measures (staff measures). The daily assessments were performed by the registered nurse responsible for the patients' care on that day and could thus be performed by various individuals from day to day. The proxy version of the Integrated Palliative Care Outcome Scale (IPOS) was used to assess the patient's symptoms and relatives' concerns [17]. The IPOS-variables pain and anxiety were reported on an ordinal scale estimating how much the patient was 
affected, ranging from 0 (not at all) to 4 (overwhelmingly/worst pain imaginable) and these numerical estimates were then used to calculate the pain and anxiety levels. The Richmond Agitation and Sedation Scale (RASS) was used to indicate the level of patient alertness $(+4$ combative via 0 alert and calm to -5 unarousable) [18, 19]. Performance status was assessed according to the Eastern Cooperative Oncology Group (ECOG/WHO) performance status (0 fully active to 5 dead) and the Confusion Assessment Method (CAM) instrument was used for assessing delirium in a Yes/ No format [20, 21].

\section{Study size}

This is a descriptive study, and no sample size calculation was performed.

\section{Statistical methods and missing data}

Descriptive statistics are presented with both means and medians as appropriate. T-tests were used to compare age and survival, and, for other variables, the following non-parametric tests were applied: chi-square test to compare proportions, Mann-Whitney U test to compare independent groups and Wilcoxon signed-rank test to compare dependent groups.
From initiation of CSCI until day 3, there were missing data on an average of 5 patients per day of the total study cohort, though in no case for more than one consecutive day. For missing data, the last observation carried forward was used. Analysis was performed using SPSS Version 26.

Ethical approval (2018/2103-31/1) was obtained from the Regional Ethical Review Board (Stockholm, Sweden) and all participants consented to inclusion in the study.

\section{Results}

During the study period, 321 patients were prescribed CSCI and a total of 93 were included in the study intended to be followed prospectively. Of those not included, $88 \%$ were assessed as too ill to give formal consent and $12 \%$ abstained (Fig. 1). Mean age of the included patients was 76.3 years (median 77 years), $57 \%$ were women, (Table 1). Indications for CSCI were: inability to swallow due to deterioration of general condition in 49 (53\%) patients, uncontrolled pain with oral pain medication in 27 (29\%) patients, bowel obstruction in 6 (6\%) patients and unspecified reasons in 11 (12\%) patients. On day 0 (initiation of CSCI), the mean pain score was 2.2 (median 2), with 5 (5\%) patients rating no pain (Table 2). Two thirds of the reported pain mechanisms were combined

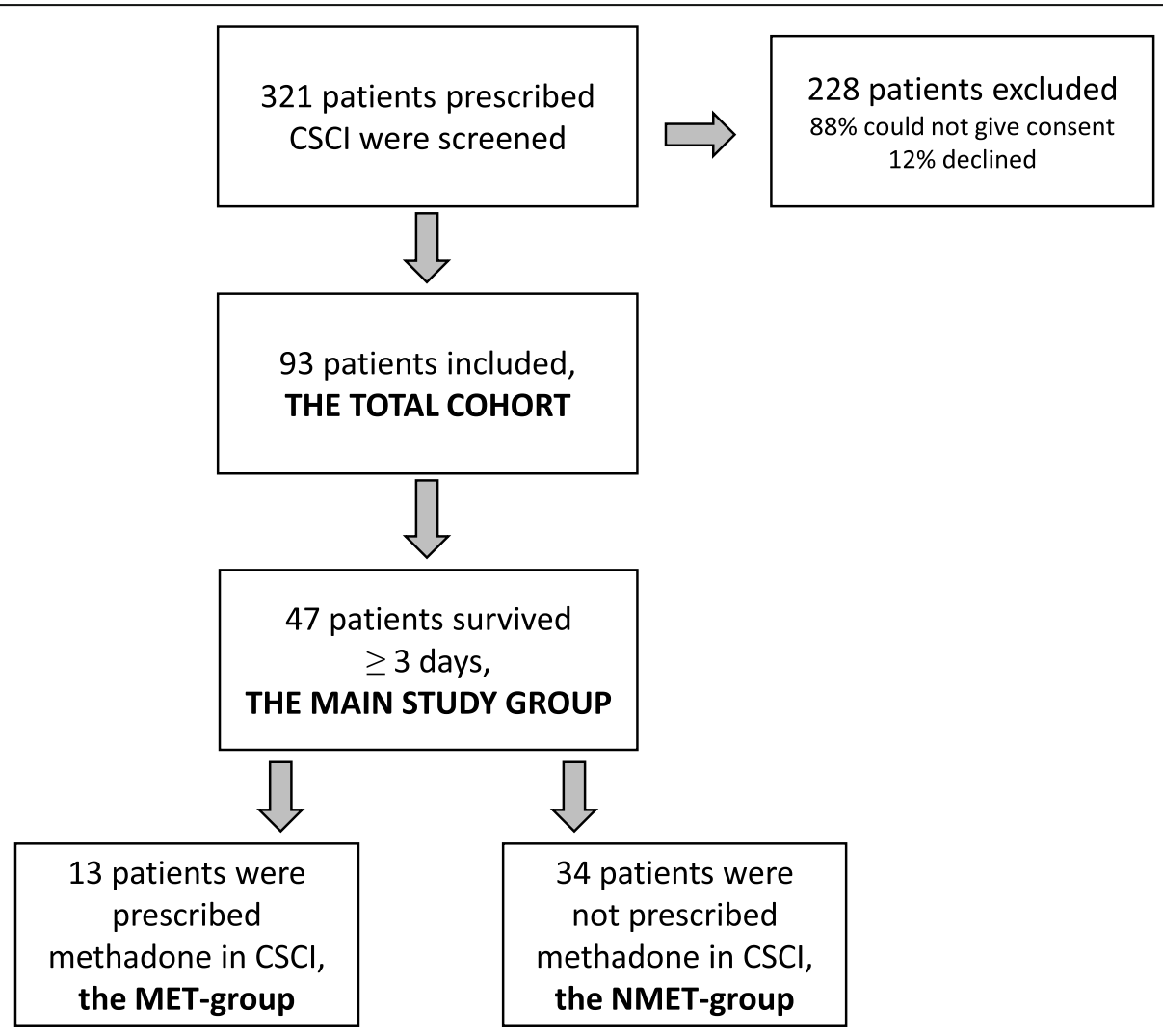

Fig. 1 Flow chart of patient selection 
Table 1 Patient characteristics and pain mechanisms on the day of CSCl initiation

\begin{tabular}{|c|c|c|c|c|}
\hline & Total & Main study & $\geq 3$ days of survival & \\
\hline & cohort & Total & Methadone in $\mathrm{CSCl}$ & No methadone in $\mathrm{CSCl}$ \\
\hline & $n=93$ & $n=47$ & $n=13$ & $n=34$ \\
\hline Females $n(\%)$ & $53(57)$ & $25(53)$ & $5(38)$ & $19(56)$ \\
\hline Age years & & & & \\
\hline mean (SD) & $76.3(10.6)$ & $75.6(12.1)$ & $68.7(11.7)$ & $78.2(11.5)^{*}$ \\
\hline median (IQR) & $77(12)$ & $76(16)$ & $71(14.5)$ & $77.5(16.3)$ \\
\hline Survival days & & & & \\
\hline mean $(S D)^{a}$ & $8(10)$ & $9(9)$ & $13(8)$ & $8(10)^{*}$ \\
\hline median (IQR) & $4(5)$ & $5(9)$ & $14(14)$ & $4(5)$ \\
\hline Midazolam & & & & \\
\hline used midazolam n (\%) & $63(68)$ & $30(64)$ & $7(54)$ & $23(68)$ \\
\hline Dose, mg/24h & & & & \\
\hline mean (SD) & $8.0(11)$ & $7.1(9)$ & $18.8(11.2)$ & $8.7(7.4)$ \\
\hline median (IQR) & $5(10)$ & $5(10)$ & $20(25)$ & $6.3(5)$ \\
\hline range (mg) & $0-50$ & $0-37.5$ & $2.5-31$ & $2.5-37.5$ \\
\hline Performance status & & & & \\
\hline mean (SD) & $3.4(0.9)$ & $3.3(1)$ & $3.4(0.9)$ & $3.5(0.5)$ \\
\hline median (IQR) & $4(1)$ & $4(\mathrm{QQR} 1)$ & $4(1)$ & $4(1)$ \\
\hline Reported pain mechanism $n$ (\%) & $71(76)$ & $37(80)$ & $10(77)$ & $25(53)$ \\
\hline Mixed nociceptive and neuropathic pain & $47(66)$ & $26(70)$ & $6(60)$ & $18(72)$ \\
\hline Nociceptive pain & $19(27)$ & $6(16)$ & $2(20)$ & $4(16)$ \\
\hline Neuropathic pain & $5(7)$ & $5(14)$ & $2(20)$ & $3(12)$ \\
\hline Malignant diagnoses $n(\%)$ & & & & \\
\hline Gastrointestinal (other than pancreas) & $25(27)$ & $12(26)$ & $3(23)$ & $9(26)$ \\
\hline Lung & $19(21)$ & $11(23)$ & $5(38)$ & $6(18)$ \\
\hline Urogenital (other than prostate) & $11(12)$ & $6(13)$ & $2(15)$ & $4(12)$ \\
\hline Pancreas & $7(8)$ & $2(4)$ & & $2(6)$ \\
\hline Breast & $7(8)$ & $3(6)$ & & $3(9)$ \\
\hline Hematological & $5(5)$ & $3(6)$ & $1(8)$ & $2(6)$ \\
\hline Prostate & $2(2)$ & $1(2)$ & & $1(3)$ \\
\hline Head and neck & $2(2)$ & $1(2)$ & & $1(3)$ \\
\hline Skin & $1(1)$ & $1(2)$ & $1(8)$ & \\
\hline Other/unknown origin & $6(6)$ & $3(6)$ & $1(8)$ & $2(6)$ \\
\hline Non-malignant diagnoses $n(\%)$ & & & & \\
\hline lung fibrosis & $2(2)$ & $2(4)$ & & $2(6)$ \\
\hline COPD & $2(2)$ & & & \\
\hline Heart failure & $2(2)$ & & & \\
\hline Renal failure & $1(1)$ & $1(2)$ & & $1(3)$ \\
\hline Stroke & $1(1)$ & $1(2)$ & & $1(3)$ \\
\hline
\end{tabular}

${ }^{\mathrm{a}}$ After exclusion of one outlier with 125 days of survival

Significance of difference between the subgroups of the main study group that were prescribed methadone in $\mathrm{CSCl}(n=13)$ and those who were not $(n=34):^{*} p<0.05$

This table shows the basic characteristics of the groups analyzed in the study on the day when the continuous subcutaneous infusion was started. The total cohort was all 93 patients who received continuous subcutaneous infusion (CSCl) and were included. The main study group consisted of the 47 patients who survived at least 3 days. Of these, 13 patients were prescribed methadone in $\mathrm{CSCl}$ and 34 were not.

( $n$ number of patients, SD standard deviation, IQR inter quartile range) 
Table 2 Pain and opioid doses

\begin{tabular}{|c|c|c|c|c|c|c|c|}
\hline & \multirow{4}{*}{$\begin{array}{l}\begin{array}{l}\text { Total } \\
\text { cohort }\end{array} \\
n=93 \\
\text { Day } 0\end{array}$} & \multicolumn{6}{|c|}{ Main study group, $\geq 3$ days of survival } \\
\hline & & \multirow{2}{*}{\multicolumn{2}{|c|}{$\begin{array}{l}\text { Total } \\
n=47(13+34)\end{array}$}} & \multirow{2}{*}{\multicolumn{2}{|c|}{$\begin{array}{l}\text { Methadone in CSCI } \\
n=13\end{array}$}} & \multirow{2}{*}{\multicolumn{2}{|c|}{$\begin{array}{l}\text { No methadone in CSCI } \\
n=34\end{array}$}} \\
\hline & & & & & & & \\
\hline & & Day 0 & Day 3 & Day 0 & Day 3 & Day 0 & Day 3 \\
\hline \multicolumn{8}{|l|}{ Level of pain $(0-4)^{a}$} \\
\hline Mean (SD) & $2.2(1.1)$ & $2.2(1.2)$ & $1.5(1.2)^{* * *}$ & $2.9(1.0)$ & $2.1(1.3)^{*}$ & $2.0(1.1)$ & $1.2(1.1)^{* * *}$ \\
\hline Median (IQR) & $2(2)$ & $2(2)$ & $2(2)$ & $3(1)$ & $2(2)$ & $2(2)$ & $1(1)$ \\
\hline Severe to overwhelming pain (scores 3-4) $n$ (\%) & $39(42)$ & $21(45)$ & $9(19)^{* * *}$ & $10(77)$ & $6(46)^{*}$ & $11(32)$ & $3(9)^{* * *}$ \\
\hline \multicolumn{8}{|l|}{ MEDD $^{\mathrm{b}}$ of opioids, $m g$} \\
\hline Mean (SD) & $179(175)$ & $184(181)$ & $205(182)^{*}$ & $306(257)$ & $354(225)$ & $133(108)$ & $142(116)^{*}$ \\
\hline Median (IQR) & $120(169)$ & $123(151)$ & $150(210)$ & $240(310)$ & 300 (193) & $113(120)$ & 105 (125) \\
\hline Range & $22.5-1020$ & $22.5-1020$ & $30-870$ & $22.5-1020$ & $75-870$ & $30-435$ & $30-563$ \\
\hline \multicolumn{8}{|l|}{ Methadone, mg } \\
\hline Mean (SD) & $5.5(4.6)$ & - & - & $7.5(4.8)$ & $7.7(4.5)$ & - & - \\
\hline Median (IQR) & $5(7.5)$ & - & - & $5(5)$ & $5(5)$ & - & - \\
\hline Range & $0-20$ & - & - & $2.5-20$ & $5-20$ & - & - \\
\hline
\end{tabular}

${ }^{\mathrm{a}}$ Ordinal scale from 0 (not at all affected by pain) to 4 (overwhelmingly)

${ }^{\text {b}}$ Total morphine equivalent (oral) daily doses

Significance of difference from day 0 to day $3:^{*} p<0.05{ }^{* *} p<0.01 ;{ }^{* *} p \leq 0.001$. The comparisons are made for the main study group ( $n=47$ ), for the MET group $(n=13)$ and the NMET group $(n=34)$, respectively

The table refers partly to the situation at the day for start of the continuous subcutaneous infusion (CSCI), and partly 3 days later. It is divided into the different groups analyzed in the study, i.e. the total cohort which is all 93 patients who received $\mathrm{CSCl}$ from day 0 and the 47 patients who survived at least 3 days and who make up the main study group. The 13 patients in the main study group who were prescribed methadone in $\mathrm{CSCl}$ are the MET group and the 34 who were not prescribed methadone are the NMET group. The table shows levels of pain at the different times, and also the doses of opioids that the patients were prescribed, including methadone.

(n number of patients, SD standard deviation, IQR inter quartile range)

nociceptive and neuropathic. For other characteristics, see Table 1.

Three patients, one of whom received methadone, experienced local erythema which disappeared within one day after changing the injection site. In all three cases, the needle had been in place for at least 5 days.

\section{Patients with $\mathbf{3}$ days or more of survival time}

To enable the study of the effects and adverse effects of opioids over time, patients with no pain and with a survival of less than 3 days, as well as patients who also received additional palliative sedation, were excluded from further analyses, leaving 47 patients in the main study group. This group included patients receiving midazolam prescribed for anxiety, but not for sedation. The median survival in this cohort was 5 days (mean 9). For further characteristics, see Table 1.

\section{Adjuvant analgesics and opioids}

Thirty-three patients (70\%) used peroral non-opioids and/or adjuvant analgesics on the day of initiation of CSCI (mean 1.7 adjuvants), including corticosteroids, paracetamol (acetaminophen), NSAIDs, antidepressants and gabapentinoids. The following opioids (oral or parenteral) were used in the main study group until the switch to CSCI: Oxycodone in $61 \%$ of the cases, morphine in $23 \%$, fentanyl patches in $14 \%$ and hydromorphone in $2 \%$ of the cases. All oral opioids were discontinued upon conversion to CSCI. The total mean morphine equivalent daily dose (MEDD) via CSCI at baseline was $184 \mathrm{mg}$. In eight cases, only opioids were used in the AIP, in 17 cases the opioids were combined with one additional drug, in 16 cases with two others and in six cases with three other drugs. For specific details on CSCIs containing methadone, see Table 3.

\section{Pain and other symptoms from day 0 to day 3}

Pain The proportion of patients severely or overwhelmingly affected by pain decreased from 45 to $19 \%(p<0.001)$ and the mean pain score from 2.2 (median 2) to 1.5 (median 2) on the five-point pain IPOS scale, (Table 2).

Alertness The mean level of alertness went from -0.2 to -1.2 , i.e. 1 point on a 10 -point scale $(p=0.001)$, (Table 4). During the same period, doses of midazolam (median 7.5 to $9.4 \mathrm{mg}, p=0.31$ ) and performance status did not change significantly.

Delirium Delirium was seen in $30 \%$ of the patients at day 0 and did not change significantly over time (day 0 
Table 3 Continuous Subcutaneous Infusions for the MET group

\begin{tabular}{|c|c|c|c|c|c|c|}
\hline $\begin{array}{l}\text { Age- } \\
\text { group }\end{array}$ & Patient & Malignancy & $\begin{array}{l}\text { Max Methadone dose } / 24 h . \text { in } \\
\text { CSCl (mg) }\end{array}$ & $\begin{array}{l}\text { Local } \\
\text { toxicity }\end{array}$ & $\begin{array}{l}\text { Regular opioid in } \\
\text { CSCI }\end{array}$ & Other drugs in $\mathrm{CSCl}$ \\
\hline \multirow[t]{2}{*}{$40-49$} & 1 & Liver & 20 & no & morphine & midazolam, haloperidol \\
\hline & 4 & Thyroid & 10 & no & hydromorphone & $\begin{array}{l}\text { midazolam, hyoscine butylbromide, } \\
\text { metoclopramide }\end{array}$ \\
\hline \multirow[t]{4}{*}{$60-69$} & 2 & Abdominal & 5 & no & oxycodone & hyoscine butylbromide \\
\hline & 6 & Lung & 5 & no & oxycodone & midazolam, hyoscine butylbromide, haloperidol \\
\hline & 7 & Lung & 10 & no & hydromorphone & midazolam, metoclopramide \\
\hline & 13 & Lung & 5 & no & hydromorphone & midazolam, hyoscine butylbromide, haloperidol \\
\hline \multirow[t]{5}{*}{$70-79$} & 5 & $\begin{array}{l}\text { B-cell } \\
\text { lymfoma }\end{array}$ & 7.5 & yes & oxycodone & midazolam \\
\hline & 8 & Bladder & 5 & no & oxycodone & \\
\hline & 9 & Bladder & 20 & no & hydromorphone & midazolam, haloperidol \\
\hline & 10 & Lung & 10 & no & hydromorphone & midazolam, haloperidol \\
\hline & 11 & Lung & 5 & no & hydromorphone & midazolam, haloperidol \\
\hline \multirow[t]{2}{*}{$80-89$} & 3 & Colon & 5 & no & oxycodone & \\
\hline & 12 & Merkel cell & 10 & no & oxycodone & midazolam, haloperidol \\
\hline
\end{tabular}

This table describes the characteristics of the 13 patients who were prescribed methadone in continuous subcutaneous infusion (CSCl), the MET group. By local toxicity is meant whether or not skin erythema occurred.

vs. day 3). Neither were there differences between patients under or above 75 years of age, (Table 4).

Anxiety At baseline, 52\% of the patients were reported to be anxious most of the time or always. On day 3 however, this proportion was significantly lower, $26 \%$ $(p=0.04)$, (Table 4$)$.

\section{Patients receiving methadone}

Thirteen patients received low-dose methadone added to the continuous infusion (MET). The median time of survival from initiation of CSCI was 14 days for the MET group compared with 4 days for the group of patients whose CSCIs contained no methadone (NMET), respectively $(p=0.044)$, (Table 1$)$. Of the 13 patients in the MET group, 10 were prescribed

Table 4 Adverse effects

\begin{tabular}{|c|c|c|c|c|c|c|c|}
\hline & \multirow{4}{*}{$\begin{array}{l}\begin{array}{l}\text { Total } \\
\text { cohort }\end{array} \\
n=93 \\
\text { Day } 0\end{array}$} & \multicolumn{6}{|c|}{ Main study group, $\geq 3$ days of survival } \\
\hline & & \multirow{2}{*}{\multicolumn{2}{|c|}{$\begin{array}{l}\text { Total } \\
n=47\end{array}$}} & \multirow{2}{*}{\multicolumn{2}{|c|}{$\begin{array}{l}\text { Methadone in CSCI } \\
n=13\end{array}$}} & \multirow{2}{*}{\multicolumn{2}{|c|}{$\begin{array}{l}\text { No methadone in CSCl } \\
n=34\end{array}$}} \\
\hline & & & & & & & \\
\hline & & Day 0 & Day 3 & Day 0 & Day 3 & Day 0 & Day 3 \\
\hline \multicolumn{8}{|l|}{ Alertness $^{a}$} \\
\hline Mean (SD) & $-0.5(1.2)$ & $-0.2(1)$ & $-1.2(1,7)^{* * *}$ & $0.4(0.9)$ & $-0.9(1.7)^{*}$ & $-0.4(1)$ & $-1.3(1.7)^{*}$ \\
\hline Median (IQR) & $0(1)$ & $0(2)$ & $-1(2)$ & $0(1)$ & $0(2)$ & $-0.5(1)$ & $-1(2)$ \\
\hline \multicolumn{8}{|l|}{ Delirium $^{b}$} \\
\hline Prevalence $n(\%)$ & $27(29)$ & $14(30)$ & $15(32)$ & $4(31)$ & $5(39)$ & $10(29)$ & $10(29)$ \\
\hline Prev. $<75$ years & $12(32)$ & $7(33)$ & $9(43)$ & $4(31)$ & $5(39)$ & $8(32)$ & $7(28)$ \\
\hline Prev. $\geq 75$ years & $15(27)$ & $7(27)$ & $6(23)$ & $3(30)$ & $2(20)$ & $12(27)$ & $4(9)$ \\
\hline \multicolumn{8}{|l|}{ Anxiety ${ }^{c}$} \\
\hline median (IQR) & $3(1)$ & $3(1)$ & $2(2)$ & $3(1)$ & $2(1.8)$ & $3(1.5)$ & $2(2)$ \\
\hline
\end{tabular}

${ }^{a}$ Ordinal scale from +4 (combative) to -5 (unarousable)

${ }^{\mathrm{b}}$ Prevalence of confusion/delirium (Yes/No)

'Ordinal scale from 0 (not at all) to 4 (always)

Significance of differences from day 0 to day $3: * p<0.05 ; * * * 0.001$

In this table, the status of all 93 patients regarding alertness, prevalence of delirium and anxiety on the day of initiation, day 0 , of continuous subcutaneous

infusion (CSCl) is reported under total cohort. The main study group is the 47 patients who survived at least 3 days. The changes from day 0 to day 3 in adverse

effects is shown for the total group and also for the 13 patients who received methadone in $\mathrm{CSCl}$ and the 34 patients who did not.

( $n$ number of patients, SD standard deviation, IQR inter quartile range) 
methadone for the first time on day 0 and the other 3 were previously on peroral methadone due to previous, insufficient pain control. After 3 days, the dose was unchanged in 72\%, increased in $18 \%$ and decreased in $10 \%$ of the cases. The most common starting dose of SC methadone was $5 \mathrm{mg}$ per $24 \mathrm{~h}$ (55\%), (Table 2). All the patients used methadone until the CSCI was ended, in all cases due to death.

\section{Opioids}

At baseline, the MEDD of opioids via CSCI for MET (median $240 \mathrm{mg}$ ) was almost twice the dose for NMET (median $133 \mathrm{mg}),(p=0.004)$. From days 0 to 3 there was an increase in opioid doses for NMET $(p=0.02)$.

\section{Pain and other symptoms from day 0 to day 3}

Pain On day 0, MET compared with NMET patients had more severe pain $(p=0.02)$ and a higher proportion of severe/overwhelming pain, $77 \%$ vs. $32 \%(p=0.009)$, (Table 2). On day 3, pain scores were significantly reduced for both MET and NMET patients $(p=0.04$ and $p=0.001$, respectively) and the proportion of severe pain was lower, (Table 2).

Alertness MET started at a slightly higher alertness level than NMET $(p=0.02)$. The levels dropped from 0.4 to -0.9 (median 0 to $0 ; p=0.02$ ) and from -0.4 to -1.3 (median -0.5 to $-1 ; p=0.02$ ), respectively, (Table 4 ).

There were no significant differences between MET and NMET over time regarding doses of midazolam $(p=0.054)$, performance status, anxiety, or prevalence of delirium, (Table 1 and Table 4).

\section{Serious adverse effects}

One MET patient had a respiratory ratio lower than eight breaths per minute on days three and four. No interventions were needed, and from day five he had normal respiratory ratios until death on day nine.

\section{Discussion}

In this study on symptom relief during the very last days of life, we report that the use of AIP for CSCI for pain control in dying patients contributed to improved analgesia with no clinically significant change in adverse effects. In addition, CSCI with low-dose methadone in combination with other regular opioids was prescribed at the individual physician's discretion and resulted in improved analgesia for patients with the most severe pain.

Several studies and guidelines report on the treatment of severe pain in patients in palliative care in less advanced stages [3, 22-24]. However, few studies investigate pain and symptom management in the imminently dying, due to the well-known problems related to symptom assessment $[25,26]$. The short median survival time of four days confirms that the patients in this study were at the very end of life. In this setting, the most common reason for initiating CSCI was general deterioration causing impaired oral intake. Another major reason was to provide better pain relief by converting to parenteral drug delivery and, when judged necessary, by adding parenteral methadone. The need for better pain relief may be due to mixed nociceptive and neuropathic pain in two thirds of the patients in this study, a combination of pain mechanisms often difficult to treat [14].

Significant reduction in pain was seen for the entire group of patients who received CSCI with opioids for pain and who could be followed for at least three days. This was regardless of whether the pain was measured as the proportion of patients with severe pain or as the median and average pain scores based on the Likert scale for pain in the IPOS [17]. Advantages in CSCI administration of opioids in relation to pain control include a more stable serum concentration of the drug with avoidance of end-of-dose interval breakthrough pain and less adverse effects occurring at high peak concentrations following intermittent injections which allows a more adequate opioid dose titration $[6,27,28]$. In the imminently dying patients a rotation from oral intake to parenteral routes might be especially beneficial, as the oral route, including swallowing and absorption, might be unreliable in the last days and hours of life.

In this study, it was not recorded whether the same opioid was used when switching to CSCI or whether an alternative opioid was used. There may exist a crosstolerance between opioids, meaning that a different opioid has a better analgesic effect than expected from equianalgesic tables [29]. However, a review by Schuster et al. 2018 confirmed the stated findings in the Cochrane review from 2004, that although widely practiced, robust evidence for the benefit of opioid rotation is still lacking [30, 31].

Patients who required the addition of methadone for analgesia had higher pain scores and opioid doses at initiation of CSCI. Thus, the use the co-prescription of low-dose methadone with another opioid for CSCI via AIP was mainly initiated in patients with complex pain of high intensity, in order to improve pain control without large dose escalations of the regular opioid. This is in line with the study by Mercadante et al, that described how addition of methadone to another opioid in patients with cancer pain may reduce the need for opioid dose escalation [32]. As shown in this study, the apparent beneficial analgesic effect adding of low-dose methadone to another opioid for administration by CSCI is promising and reflects observations reported for oral administration [8-12]. 
There was a statistically significant decrease in alertness $(p<0.001)$. However, the clinical impact is probably minor as the change was 1.0 in a 10 -grade scale, i.e. a 10 $\%$ deterioration, in acutely dying patients. Besides this, there were neither any increase in intensity of other adverse symptoms nor any serious adverse effects that demanded specific interventions. Moreover, we observed no significant differences over time or between MET and NMET regarding performance status, anxiety levels or doses of the anxiolytic midazolam. These observations agree with the general observation that adverse effects such as sedation, constipation, and respiratory depression are associated with the pharmacology of opioids as a class, and similar reactions are expected regardless of route [28].

Notably, those in the subgroup MET had higher total opioid doses, still they survived marginally longer. The MET group's longer survival from introduction to death may possibly be explained by their more complex pain situation, possibly resulting in an earlier introduction of CSCI.

Particularly interesting is that the prevalence of delirium in the main study group did not change over time and did not differ between patients younger or older than 75 years of age. To the best of our knowledge, differences in adverse effects following introduction of CSCI for pain in different age groups has not been described before, but our findings are consistent with previous studies indicating that a steady infusion of subcutaneous drugs may be better tolerated $[6,33]$.

Problems with local skin irritation at the site of CSCI has been associated with methadone but are reported to resolve with site rotation [15, 34-36]. In our prospective study, only low-doses of methadone were infused and we found only three cases of skin irritation, two in the NMET group and one in the MET group. The needle had been in the same place for at least five days which, therefore, may be as likely an explanation for the dermal erythema as the drugs in the CSCI. We therefore suggest that the risk of skin irritation should not be considered a major limiting factor for the use of methadone in CSCI.

There was a significant difference in mean age between the MET group, 68 years, and the NMET group, 78 years, $(p<0.05)$. We described a similar difference in a study from 2020 on a different sample [13]. To the best of our knowledge this has not been studied before and we do not know the underlying reason.

We do recognize some limitations of the study. First, as accounted for in the methods section, all patients receiving a CSCI were not included, usually due to illness and of ability to provide informed consent, as well as some patients refraining from participation. Second, as methadone, according to clinical guidelines, was mainly prescribed to patients with the most severe pain, the MET and NMET groups differed significantly at baseline as regards pain intensity and MEDD. Still, such comparisons of subgroups are of interest, as they reflect a clinical reality. Comparable control groups are difficult to achieve in a population of dying patients in need of parenteral drug administration, and randomization with control groups is seldom possible, for ethical reasons. Third, due to the severe illnesses of the patients, observer ratings had to be used. By definition, observer assessment may not directly reflect the patient's experiences, meanwhile, they allow studies in the last days and hours of life, on an important patient group that is often excluded from studies. The assessments were based on subjective judgements by the registered nurses who performed the registrations. Consequently, the assessments came to a certain extent to depend on each individual's level of knowledge, skills, and personal attitudes. Finally, this is a single-center study reflecting the experiences at one particular setting.

Strengths include the prospective design until death and the use of validated instruments for symptom assessments. Another strength is that the proxy assessments were performed by trained personnel, which may have contributed to improved assessments of adverse effects [37].

\section{Conclusions}

Regardless of age, CSCI via AIP for pain seems effective in reducing pain in dying patients without any substantial increase of adverse effects such as delirium or respiratory depression. An addition of low-dose methadone may be beneficial for CSCIs for patients with severe cancer pain at the end of life. The effectiveness of low-dose methadone in combination with the patient's regular opioid needs further investigation, preferably with a randomized controlled trial.

\section{Abbreviations}

CSCl: Continuous subcutaneous infusion; AIP: Ambulatory infusion pump; CAM: Confusion Assessment Method; ECOG: Eastern Cooperative Oncology Group; hrs.: Hours; IPOS: Integrated Palliative Care Outcome Scale; IQR: Inter quartile range; MEDD: Morphine equivalent daily dose of opioids; MET: Patients with methadone as add-on; mg: Milligrams; n: Number; NMET: Patients on opioids other than methadone only; NSAID: Non-steroidal anti-inflammatory drug; RASS: Richmond Agitation and Sedation Scale; SC: Subcutaneous; SD: Standard deviation; STROBE: Strengthening the Reporting of Observational Studies in Epidemiology

\section{Acknowledgments}

The authors would like to thank all the staff working in the palliative departments at Stockholm Sjukhem for their valuable participation with the data collection and Sara Runesdotter for her help with the statistics. David Boniface is acknowledged for linguistic revision.

\section{Authors' contributions}

All authors (PF, SL, PK, PS) contributed to the design of the work or data collection, analysis, and interpretation of data; participated in revision; gave 
the final approval of the version to be published; and agreed to be responsible for the work. The authors read and approved the final manuscript.

\section{Funding}

This work was supported by the Stockholm Sjukhem Foundation. The funding body did not participate in any part of the study (neither in the design, collection of data, analysis, interpretation nor in writing of the manuscript). Open Access funding provided by Karolinska Institute.

\section{Availability of data and materials}

The datasets used and/or analyzed during the current study are available from the corresponding author on reasonable request.

\section{Ethics approval and consent to participate}

Ethical approval (2018/2103-31/1) was obtained from the Regional Ethical Review Board (Stockholm, Sweden) and all participants consented to inclusion in the study. The ethics permit referred to written consent, with or without assistance, depending on the situation. Therefore, each individual patient who was able to sign the consent did so himself and in cases where the general condition caused physical difficulties in writing (because of frailty caused by the dying process), the consent was filled in, with the patient's approval, together with the patient.

\section{Consent for publication}

Not applicable.

\section{Competing interests}

The authors declare that they have no competing interests.

\section{Author details}

${ }^{1}$ Department of Oncology Pathology, Karolinska Institutet, Stockholm, Sweden. ${ }^{2}$ Palliative Medicine, Stockholms Sjukhem Foundation, Stockholm, Sweden. ${ }^{3}$ Department of Circulation and Medical Imaging, Faculty of Medicine, Norwegian University of Science and Technology, Trondheim, Norway. ${ }^{4}$ European Palliative Research Centre, Department of Clinical and Molecular Medicine, Faculty of Medicine, Norwegian University of Science and Technology, Trondheim, Norway. ${ }^{5}$ Department of Anesthesiology and Intensive Care medicine, St. Olavs Hospital, Trondheim University Hospital, Trondheim, Norway.

Received: 19 July 2020 Accepted: 5 November 2020

Published online: 10 November 2020

\section{References}

1. van den Beuken-van Everdingen $M H$, Hochstenbach LM, Joosten EA, TjanHeijnen VC, Janssen DJ. Update on Prevalence of Pain in Patients With Cancer: Systematic Review and Meta-Analysis. J Pain Symptom Manag. 2016;51(6):1070-90 e1079.

2. WHO, Palliative Care. https://www.who.int/news-room/fact-sheets/detail/ palliative-care. Last accessed July 7, 2020.

3. Caraceni A, Hanks G, Kaasa S, Bennett MI, Brunelli C, Cherny N, Dale O, De Conno F, Fallon M, Hanna M, et al. Use of opioid analgesics in the treatment of cancer pain: evidence-based recommendations from the EAPC. Lancet Oncol. 2012;13(2):e58-68.

4. Klepstad P, Kaasa S, Cherny N, Hanks G, de Conno F. Pain and pain treatments in European palliative care units. A cross sectional survey from the European Association for Palliative Care Research Network. Palliat Med. 2005;19(6):477-84

5. Oshiro T, Oshiro H, Tanimizu M. continuous subcutaneous injection therapy in end-of-life symptoms of Cancer and non-Cancer patients. Gan Kagaku Ryoho Cancer Chemother. 2018;45(Suppl 1):111-3.

6. Thomas T, Barclay S: Continuous subcutaneous infusion in palliative care: a review of current practice. Int J Palliat Nurs 2015, 21(2):60, 62-64.

7. $\mathrm{WHO}$, Infusion pumps, ambulatory. https://www.who.int/medical_devices/ innovation/hospt equip_15.pdf?ua=1. Last accessed July 7, 2020.

8. Wallace E, Ridley J, Bryson J, Mak E, Zimmermann C. Addition of methadone to another opioid in the management of moderate to severe cancer pain: a case series. J Palliat Med. 2013;16(3):305-9.
9. Salpeter SR, Buckley JS, Bruera E. The use of very-low-dose methadone for palliative pain control and the prevention of opioid hyperalgesia. J Palliat Med. 2013;16(6):616-22.

10. Salpeter SR, Buckley JS, Buckley NS, Bruera E. The use of very-low-dose methadone and haloperidol for pain control in the hospital setting: a preliminary report. J Palliat Med. 2015;18(2):114-9.

11. Courtemanche F, Dao D, Gagne F, Tremblay L, Neron A. Methadone as a Coanalgesic for palliative care Cancer patients. J Palliat Med. 2016;19(9):972-8.

12. Furst $P$, Lundstrom $S$, Klepstad $P$, Runesdotter $S$, Strang P. Improved pain control in terminally ill Cancer patients by introducing low-dose Oral methadone in addition to ongoing opioid treatment. J Palliat Med. 2018; 21(2):177-81.

13. Furst $P$, Lundstrom $S$, Klepstad $P$, Strang $P$. The use of low-dose methadone as add-on to regular opioid therapy in Cancer-related pain at end of life: a National Swedish Survey in specialized palliative care. J Palliat Med. 2020; 23(2):226-32.

14. Furst $P$, Lundstrom $S$, Strang $P$. Methadone in Swedish specialized palliative care-is it the magic bullet in complex cancer-related pain? PLoS One. 2020; 15(4):e0230845.

15. Shaiova L, Berger A, Blinderman CD, Bruera E, Davis MP, Derby S, Inturrisi C, Kalman J, Mehta D, Pappagallo M, et al. Consensus guideline on parenteral methadone use in pain and palliative care. Palliat Support Care. 2008;6(2): 165-76.

16. Vandenbroucke JP, von Elm E, Altman DG, Gotzsche PC, Mulrow CD, Pocock SJ, Poole C, Schlesselman JJ, Egger M. Strengthening the Reporting of Observational Studies in Epidemiology (STROBE): explanation and elaboration. Epidemiology (Cambridge, Mass). 2007;18(6):805-35.

17. Schildmann EK, Groeneveld El, Denzel J, Brown A, Bernhardt F, Bailey K, Guo P, Ramsenthaler C, Lovell N, Higginson IJ, et al. Discovering the hidden benefits of cognitive interviewing in two languages: the first phase of a validation study of the integrated palliative care outcome scale. Palliat Med. 2016;30(6):599-610.

18. Sessler CN, Gosnell MS, Grap MJ, Brophy GM, O'Neal PV, Keane KA, Tesoro EP, Elswick RK. The Richmond agitation-sedation scale: validity and reliability in adult intensive care unit patients. Am J Respir Crit Care Med. 2002; 166(10):1338-44.

19. Arevalo JJ, Brinkkemper T, van der Heide A, Rietjens JA, Ribbe M, Deliens L, Loer SA, Zuurmond WW, Perez RS. Palliative sedation: reliability and validity of sedation scales. J Pain Symptom Manag. 2012;44(5):704-14.

20. Oken MM, Creech RH, Tormey DC, Horton J, Davis TE, McFadden ET, Carbone PP. Toxicity and response criteria of the eastern cooperative oncology group. Am J Clin Oncol. 1982;5(6):649-55.

21. Grover S, Kate N. Assessment scales for delirium: a review. World J Psychiatry. 2012;2(4):58-70.

22. Kongsgaard U, Kaasa S, Dale O, Ottesen S, Nordøy T, Hessling SE, von Hofacker S, Bruland Ø S, Lyngstadaas A: NIPH Systematic Reviews: Executive Summaries. In: Palliative Treatment of Cancer-Related Pain. edn. Oslo, Norway: Knowledge Centre for the Health Services at The Norwegian Institute of Public Health (NIPH); 2005.

23. Edler-Buggy S, Birtwistle J, ElMokhallalati Y, Kindl K, Good P, Bennett MI. Regular dosing compared with as-needed dosing of opioids for management of chronic cancer pain: systematic review and meta-analysis. Pain. 2020;161(4):703-12.

24. Wiffen PJ, Wee B, Derry S, Bell RF, Moore RA. Opioids for cancer pain - an overview of Cochrane reviews. Cochrane Database Syst Rev. 2017;7: Cd012592.

25. Parsons HA, Shukkoor A, Quan H, Delgado-Guay MO, Palmer JL, Fainsinger R, Bruera E. Intermittent subcutaneous opioids for the management of cancer pain. J Palliat Med. 2008;11(10):1319-24.

26. Jordhoy MS, Kaasa S, Fayers P, Ovreness T, Underland G, Ahlner-Elmqvist M. Challenges in palliative care research; recruitment, attrition and compliance: experience from a randomized controlled trial. Palliat Med. 1999;13(4): 299-310.

27. Cools HJ, Berkhout AM, De Bock GH. Subcutaneous morphine infusion by syringe driver for terminally ill patients. Age Ageing. 1996;25(3):206-8.

28. Anderson SL, Shreve ST. Continuous subcutaneous infusion of opiates at end-of-life. Ann Pharmacother. 2004;38(6):1015-23.

29. McPherson ML. Why equianalgesic tables are only part of the answer to equianalgesia. Ann Palliat Med. 2020;9(2):537-41.

30. Quigley C. Opioid switching to improve pain relief and drug tolerability. Cochrane Database Syst Rev. 2004;(3):Cd004847. 
31. Schuster M, Bayer O, Heid F, Laufenberg-Feldmann R. Opioid Rotation in Cancer Pain Treatment A Systematic Review. Deutsches Arzteblatt Int. 2018; 115(9):135.

32. Mercadante S, Villari P, Ferrera P, Casuccio A. Addition of a second opioid may improve opioid response in cancer pain: preliminary data. Support Care Cancer. 2004;12(11):762-6.

33. Radbruch L, Trottenberg P, Elsner F, Kaasa S, Caraceni A. Systematic review of the role of alternative application routes for opioid treatment for moderate to severe cancer pain: an EPCRC opioid guidelines project. Palliat Med. 2011;25(5):578-96.

34. Bruera E, Fainsinger R, Moore M, Thibault R, Spoldi E, Ventafridda V. Local toxicity with subcutaneous methadone. Experience of two centers. Pain. 1991;45(2):141-3.

35. Mathew P, Storey P. Subcutaneous methadone in terminally ill patients: manageable local toxicity. J Pain Symptom Manag. 1999;18(1):49-52.

36. Centeno C, Vara F. Intermittent subcutaneous methadone administration in the management of cancer pain. J Pain Palliat Care Pharmacother. 2005: 19(2):7-12.

37. Zalon ML. Nurses' assessment of postoperative patients' pain. Pain. 1993; 54(3):329-34.

\section{Publisher's Note}

Springer Nature remains neutral with regard to jurisdictional claims in published maps and institutional affiliations.

- fast, convenient online submission

- thorough peer review by experienced researchers in your field

- rapid publication on acceptance

- support for research data, including large and complex data types

- gold Open Access which fosters wider collaboration and increased citations

- maximum visibility for your research: over $100 \mathrm{M}$ website views per year

At $\mathrm{BMC}$, research is always in progress. 